\title{
LEAVING THE CLASSROOM, ENTERING THE CITY: AN EDUCATIONAL EXPERIENCE OF URBAN SYNCHRONIZATION FOR THE STUDENTS OF THE MASTER OF ARCHITECTURE
}

\author{
P.J. Juan Gutiérrez ${ }^{1}$, V. Garofalo ${ }^{2}$ \\ ${ }^{1}$ Universidad de Alicante (SPAIN) \\ ${ }^{2}$ Università degli Studi di Palermo (ITALY)
}

\begin{abstract}
The teaching-learning process of drawing the city is too often unrelated to the social reality that requests it. The numerous databases available online (IGN, cadastre, google earth ...) mean, while an excellent and valuable source of information, a distorted digital simulation of the city. The multiple layers of information available (roads, vegetation, real estate, properties, roads, topography, ...) refer to a different temporality from the current one and, although they are presented simultaneously, they are far from meaning to the digital twin with which technology companies intend (on many occasions) confuse them.

The present teaching research work assumes that, in order to draw the city accordingly, it is necessary to become aware of the temporary disconnection between urban reality and the databases hosted on our web servers. This fact (the drawing of the city is constructed by fragments of other temporal moments), analysed in a teaching context, leads us to rethink the methodology of the teaching-learning process of urban drawing, in which the theory has traditionally prevailed over the practice and in which the representation of the city has had a fundamentally theoretical component.

It is with these premises that the experience developed begins: leaving the classrooms for entering the city is the first step for students to become aware of the need to first-hand contrast the information with which they work and, in addition, is evidenced as an opportunity to build a personal database, present and, above all, aware of its limitations. By analysing the different results obtained, we will be able to argue the fundamental importance of contrasting the skills and abilities acquired during the years at the university (by our students themselves) and, at the same time, being able to solve the contemporary problems that are proposed by the representation of what we call city: the set of elements (in permanent change) which make up our life in society.
\end{abstract}

Keywords: Graphic Expression, Urban Planning, Architecture, Teaching innovation, Erasmus+.

\section{INTRODUCTION}

The teaching-learning process of drawing the city is too often unrelated to the social reality that requests it. The numerous databases available online (IGN, cadastre, google earth ...) mean, while an excellent and valuable source of information, a distorted digital simulation of the city. The multiple layers of information available (roads, vegetation, real estate, properties, roads, topography, ...) refer to a different temporality from the current one and, although they are presented simultaneously, they are far from meaning to the digital twin with which technology companies intend (on many occasions) confuse them.

The present teaching research work assumes that, in order to draw the city accordingly, it is necessary to become aware of the temporary disconnection between urban reality and the databases hosted on our web servers. This fact (the drawing of the city is constructed by fragments of other temporal moments), analysed in a teaching context, leads us to rethink the methodology of the teaching-learning process of urban drawing, in which the theory has traditionally prevailed over the practice and in which the representation of the city has had a fundamentally theoretical component.

It is with these premises that the experience developed begins: leaving the classrooms for entering the city is the first step for students to become aware of the need to first-hand contrast the information with which they work and, in addition, is evidenced as an opportunity to build a personal database, present and, above all, aware of its limitations. By analysing the different results obtained, we will be able to argue the fundamental importance of contrasting the skills and abilities acquired during the years at the university (by our students themselves) and, at the same time, being able to solve the 
contemporary problems that are proposed by the representation of what we call city: the set of elements (in permanent change) which make up our life in society.

\section{METHODOLOGY}

We are going to explain our simple methodology with three steps. First, we will start talking about the context where the experience takes places and the disconnection between the parts (theory-practice, classroom-city, space-time). Secondly, we will analyze the fundamental problem that occurs during the teaching-learning process of the contemporary drawing of the city, that is, the temporal one. To finish, we will show different ways of facing the problems and being consistent about this experience. Through examples, we will explain how we can, based on a teaching methodology, to apply (in an effective and useful way) these ideas in an educational and a real context.

\subsection{Disconnection}

Let's say it soon and directly: a drawing, by definition, is disconnected from its object of representation or, in other words, acts as a filtered reflection. Besides, the drawing is always an incomplete approximation. As Marco Gaiani remember us "quality of the representation of architecture: being always an intermediate and partial result, first step of a wider and complex discussion, unable to be of being unique and inmutable final synthesis" (Gaiani 2016, 155) [1]. So, it seems obvious but this is important: the city is not the drawing. Here we have the first two disconnections:

1 A drawing is (always and by definition) an incomplete representation (in this case of the city)

2 A drawing proposes (always and by definition) a filtered image

On the other hand, the city is (something) unattainable, changing and kaleidoscopic. In the words of Eduardo Carazo "It is obvious that the city is (...) an extraordinarily complex physical and social reality (...) there is no graphic tool able to portray a real sense of that interaction of factors." (Carazo 2016, 34) [2]. There will be a (natural) disconnection between what the drawing represents and what the city really is. Not only because of the drawing itself but for the meaning of what a city implies: something bigger that any combinations of ideas. Besides, we must take into account that the desired synchronization cannot be carried out: while we are writing these lines the city has already change while the ideas besides the graphics are permanent. Therefore, we can say that we have two more disconnections:

3 The city is bigger than any significant

4 The city is permanently changing

A total of four disconnections that are (always) at the starting point of any drawing of the city. Are they important? Important or not, they are going to be part of the result, naturally and by definition so, maybe, it is going to be useful to have them into account.

\subsection{The main problem: implicit temporality}

Momentarily leaving the disconnections aside, we focus the work on its most important problem, namely, the one that has to do with temporality. We can imagine (can we?) a city (a world) without time. Something like a freeze instant, all quiet, inert, eternal, and immutable. It would be hard to get but we can imagine (too) an (almost) perfect drawing of that reality. Think about it: there is no time, there is no change so, this means that no matter how difficult, how complex an object (city) is; we are going to be able to analyze it and, consequently, to draw it. This is exactly the same as saying that the temporality problem is the original problem and, actually, the only parameter (the causing) which prevents the drawing of the city from being understood as a complete and truthful representation. Is this this way? Let's analyze the consequences of temporality in our context, that is, drawing of the city teaching-learning process:

1 The time affects to the elements that we call city. As we have seen before, the reality of the city cannot be hunted by (anything) a drawing: it's constantly changing.

2 A drawing needs time to be created. As Paul Klee writes, "Is a picture ever born suddenly? Never! It is assembled piece by piece, not differently, by the way, than a house" (Klee 1945, 58) [3] 
3 A drawing needs time to be understood (read). The end of the drawing (whatever it is) goes through a reader (maybe the artist himself?) to analyze it. This, again, requires a time different from the one to create it. As Ai Weiwei reminds us "every time you make a work, you have to do drawings when you discuss the idea with your team" (Weiwei 2011, 44) [4].

4 A drawing and its inseparable support (for example paper, canvas or, more recently, the hardware), as any object, is inside and part of our becoming. That is the same as saying that a drawing deteriorates and ages as any other material thing.

5 A drawing, by its own nature, face the time in its essence since, as Patrick Maynard reminder us, "is intrinsically the record of movement in time" (Maynard 2005, 190) [5]. Not only because need time to be created (as we defend) but because its proposal is always a filter of the time (in addition to the material space).

6 The teaching-learning process also requires time (nothing is learned suddenly, but progressively). Drawing is a way to evaluate (assess) and learn and, therefore, time plays a fundamental role since the student needs to assimilate the contents and demonstrate the skills little by little, step by step.

Therefore, as we can see, these six ways of considering the time in our context are going to be inevitable. The first one due to the nature of our object of representation, the following four ones because of the essence or the drawing itself and the last one consequence of our profession: eternal students trying to learn and to share knowledge.

\subsection{Reconnecting (a possible way to apply)}

Which can be the solution to this little mess? More than looking for the panacea or, what is the same, for something that solves this paradox, we have tried to implement a parameter into the equation that can help us to face the problem with realism and, at the same time, with effectiveness: the synchronization. Assuming that the river of the different types of time (implicit in each of our contexts) flows incessantly, it is necessary (we think) keep in mind these two ideas; on one hand it is important to be aware of the temporal variable, that is, know it and take it into consideration as another characteristic of the drawing process. On the other hand (and as important as the above) it is necessary to use the temporal information to propose some kind of (and this is the key) synchronization based on the temporal information. There are a lot of ways of develop and experiment with this synchronization, we have used, as we will explain in the following section, mainly this three:

\subsubsection{The instant}

The natural tendency of the human being, or more specifically of the researcher, is to simplify the parameters to propose a more generic solution. It can be seen in this way: the problem is complex due to the infinity of its variables. If we get to reduce the variables (to one?), the problem will (almost) disappear. And here we have the solution: complexity, understood as sum of moments, can be addressed in a particular and limited way. The instant works, this way, as a space-material field of work in which the temporal variable has been cleared. The problem of synchronization has been reduce to link or connect different instants.

\subsubsection{The overlapping}

With a level of difficulty (and complexity) greater than the previous one, we can assume that the movement that implies temporality cannot be reduced (without losing too much) in a single moment: the overlapping of different temporalities (and not necessarily instants) can be understood as a method to enrich the contexts involved. The relationship between the different overlays will be the key, the point on which to emphasize, during this way of facing the problem. The final drawing will be constructed based on different temporalities that, related, will grant the final meaning.

\subsubsection{The anachronism}

Although the proposed solutions can be part of excellent methods of analyzing the contemporary drawing of the city, there is another possibility that, without giving up the essence of the paradox, helps us to work in a contemporary way. With this election, (because this must be a previous and aware election) we are assuming the limitations of our tools, on the one hand, and the implicit error, on the other. This error can be named as anachronism and it can be supported thanks to a greater (and desired) consequence. In a research context this is (maybe) a good way to introduce the experiment and the uncontrollable (but what does time mean but lack of control?) parameter in our works. The 
historian Georges Didi-Huberman explains perfectly well in his book Before Time: Art History and anachronistic images, "always, before the image, we are before time" (Didi-Huberman 2000, 31) [6] and "the anachronism would be a fault committed with regard to the convenience of the times" (DidiHuberman 2000, 61) [6].

\section{RESULTS}

Below are shown the results of the experience carried out at the University of Alicante (in the Master in Architecture). We have divided into three categories, according to the classification explained above.

\subsection{The instant}

The idea of represent the reality with the smallest time fragments, that is, the moments (instants) that, in the same way that happens with the points in space, are elements without dimension but, at the same time, with all the significance of the time. Not surprisingly, Gastón Bachelard understood them as the true essence of time, with duration being an illusion. [7]

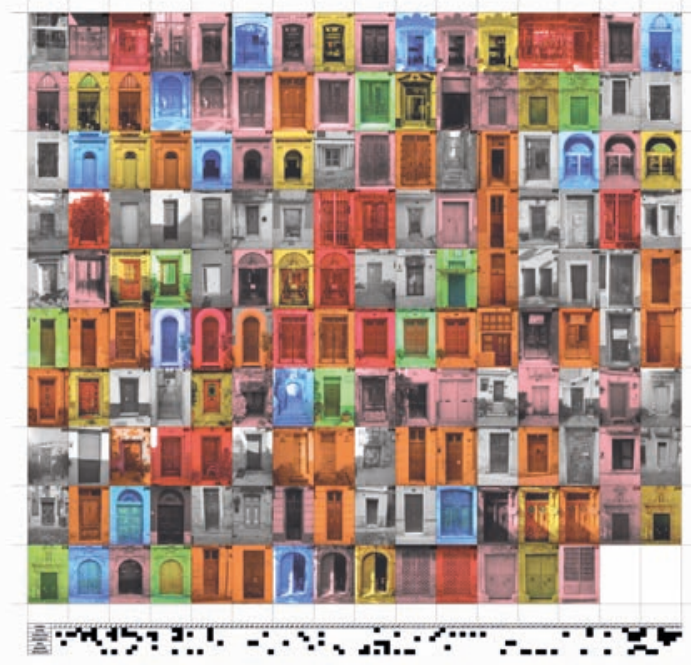

Figure 1. Doors of religious places in the historic centre of Alicante organized following a tour and filtered by colour. Students: Raúl Díaz Valera and Ignacio López Aniorte. University of Alicante.

In the Figure 1 there is a composition obtained from photographing all the doors that that belong to religious places in the historic centre of Alicante. The students, depending on the kind of religion, have coloured them. The result is a beautiful collage that also helps us to analyse in an unpublished way the type of information shown. The instant, like the point, is treated as pure and frozen information and, because of that, we can use it like the pieces of a puzzle that allows multiple solutions: depending on what we need (our intentions) we must develop one or another.

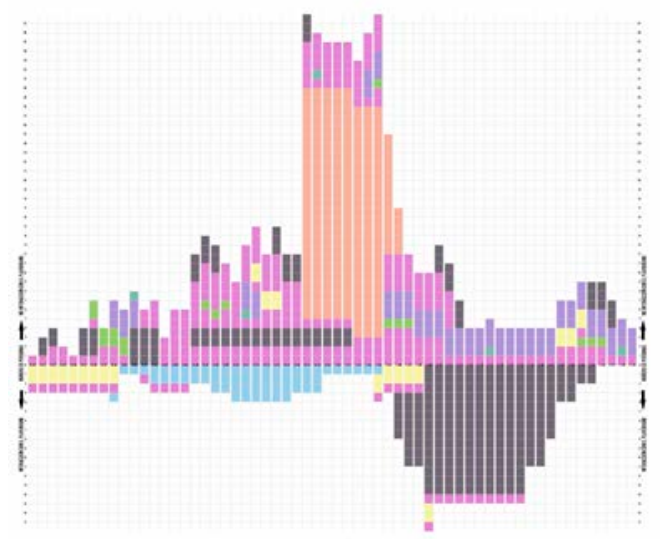

Figure 2. Timeline as a tool for organizing information. Students: Pablo López Leiva and Daniel López Yañez. University of Alicante 
In the Figure number 2 we can appreciate the same idea: the instant, containing information, is a way of understanding reality in an original aspect. The drawing is the result of the direct experience in a place and the table show different levels of information: age of the people, ways of using the space, time of a specific day ...etc. As the philosophy of Gastón Bachelard [7] the link between the different dots of information is created by us or, what is the same, the analysis of the results is as far from reality as artificial is. The drawing is a (possible) bridge to get a (previous) goal.

\subsection{The overlapping.}

From another point of view, Henri Bergson idea of time was based on the concept of duration. The instant is no such important, as the main reason to determine the consequences of the temporality is the movement called "duree" [8]. Following this idea, instead of points (instants) we have to work with lines (durations). Instead of the smallest part of the time, we are working with the construct that allows the temporal movement.

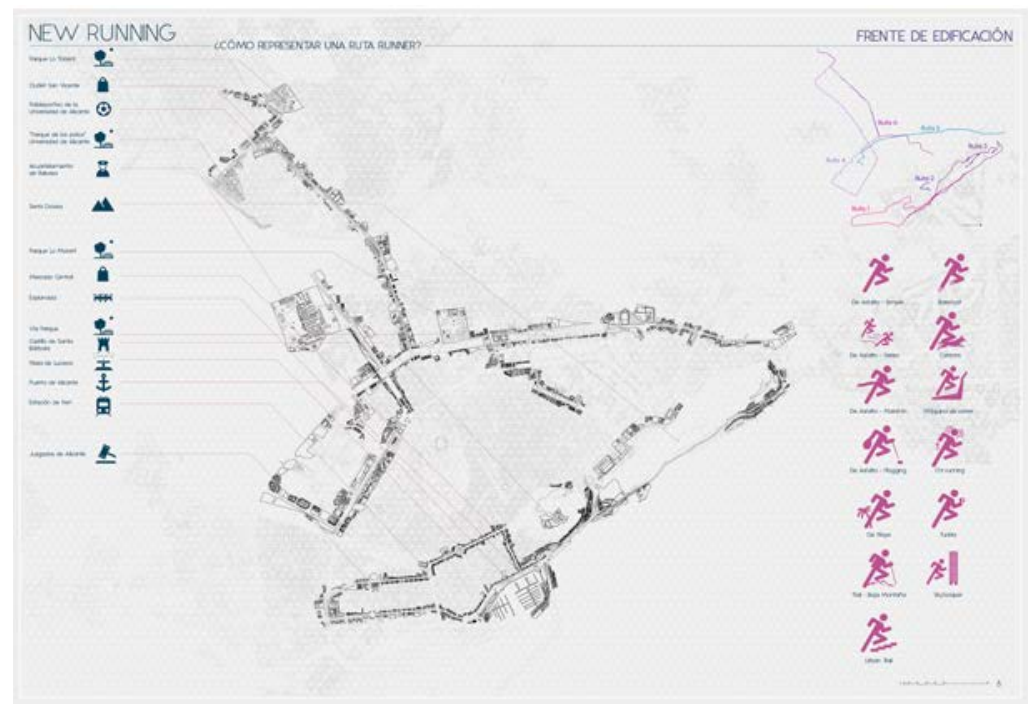

Figure 3. The drawing as a tool to represent the duration.

Student: Jose Manuel Nolasco Vidal. University of Alicante

The figure number 3 consists of a representation of the routes that athletes follow in the city. In this case we can appreciate how the city, understood as a container of movements, can be represented according to a certain action and, therefore, being sensitive to the movement that characterizes it. Although the drawing is static and, therefore, unable to accommodate time, we are able to transmit sequences due to the active role of the reader... as we pointed out above.

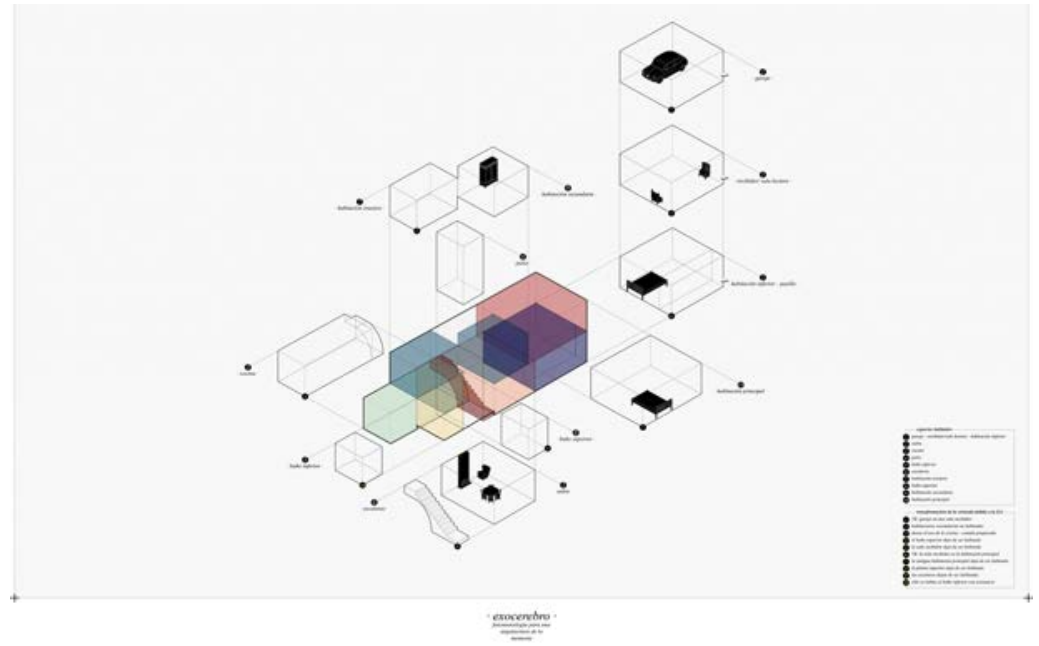

Figure 4. A drawing about the stories inside a family home. Student: Raúl Díaz Valera. University of Alicante 
Meanwhile, figure number 4 is another way of capturing the movement in a two-dimensional and static support. With it, we can analyse a house based on (some) of the stories, it contains ... so that space becomes part of the backdrop where the important thing happens, that is, the action.

\subsection{The anachronism}

The more complex way of considering the time in our drawings of the city is to consider it in all its complexity, with no intention of reducing or simplifying it, that is, assuming the paradox of the time and, what is more important, its more strange and stimulating implicit feature: the anachronism understood as contradiction [9].

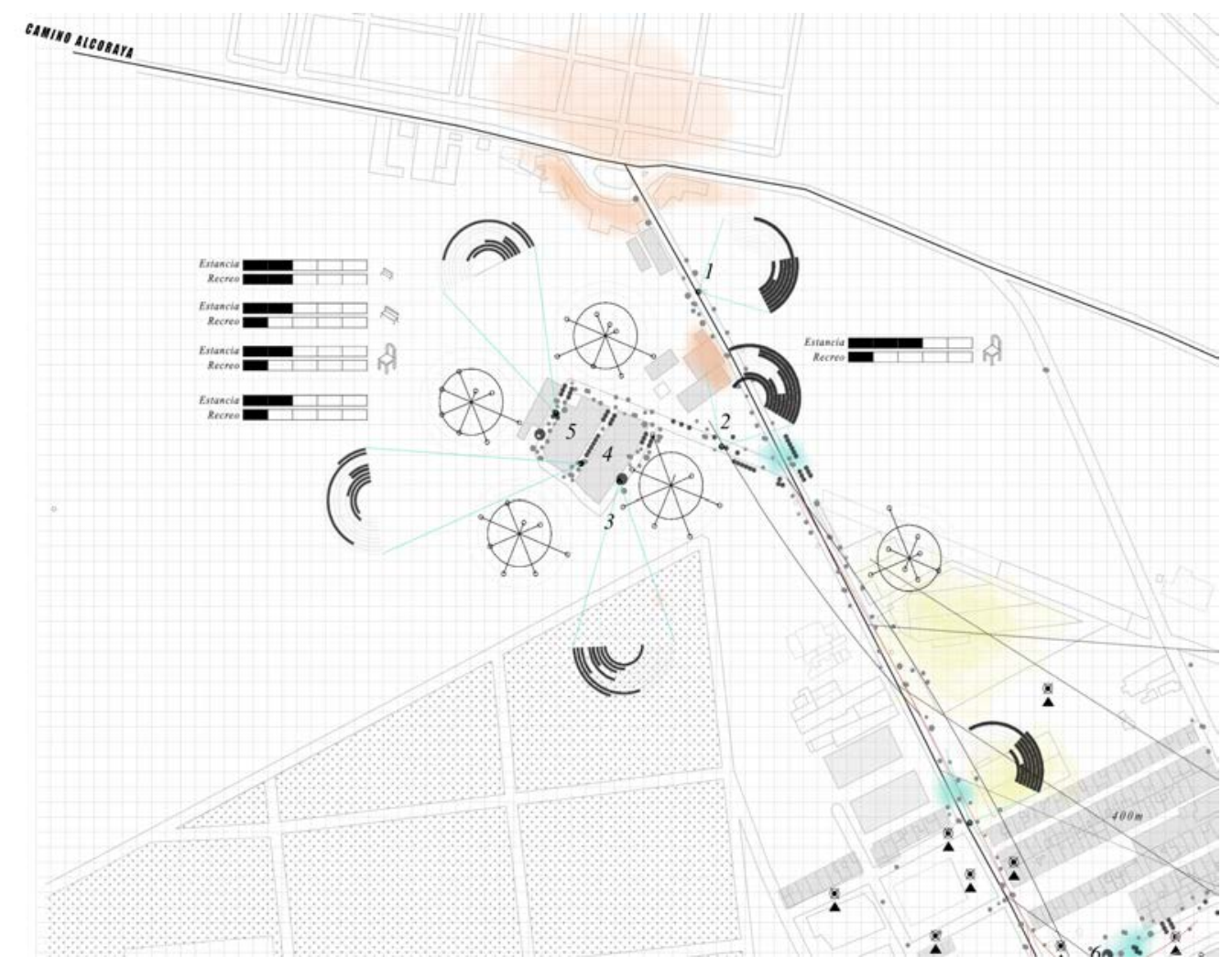

Figure 5. Assuming the complexity. Students: Luz Albadalejo Falcó,

Raquel Pérez Belmonte y Darío Vilana Palomino. University of Alicante

In the Figure 5, the drawing shows us a way to insert anachronism in the city analysis. The text mixes with the line and the colour to form a kind of palimpsest in which the information tells us about the moment, the movement, the sequence and, in addition, builds an original way to present the city and, above all, permeable to diverse readings. 


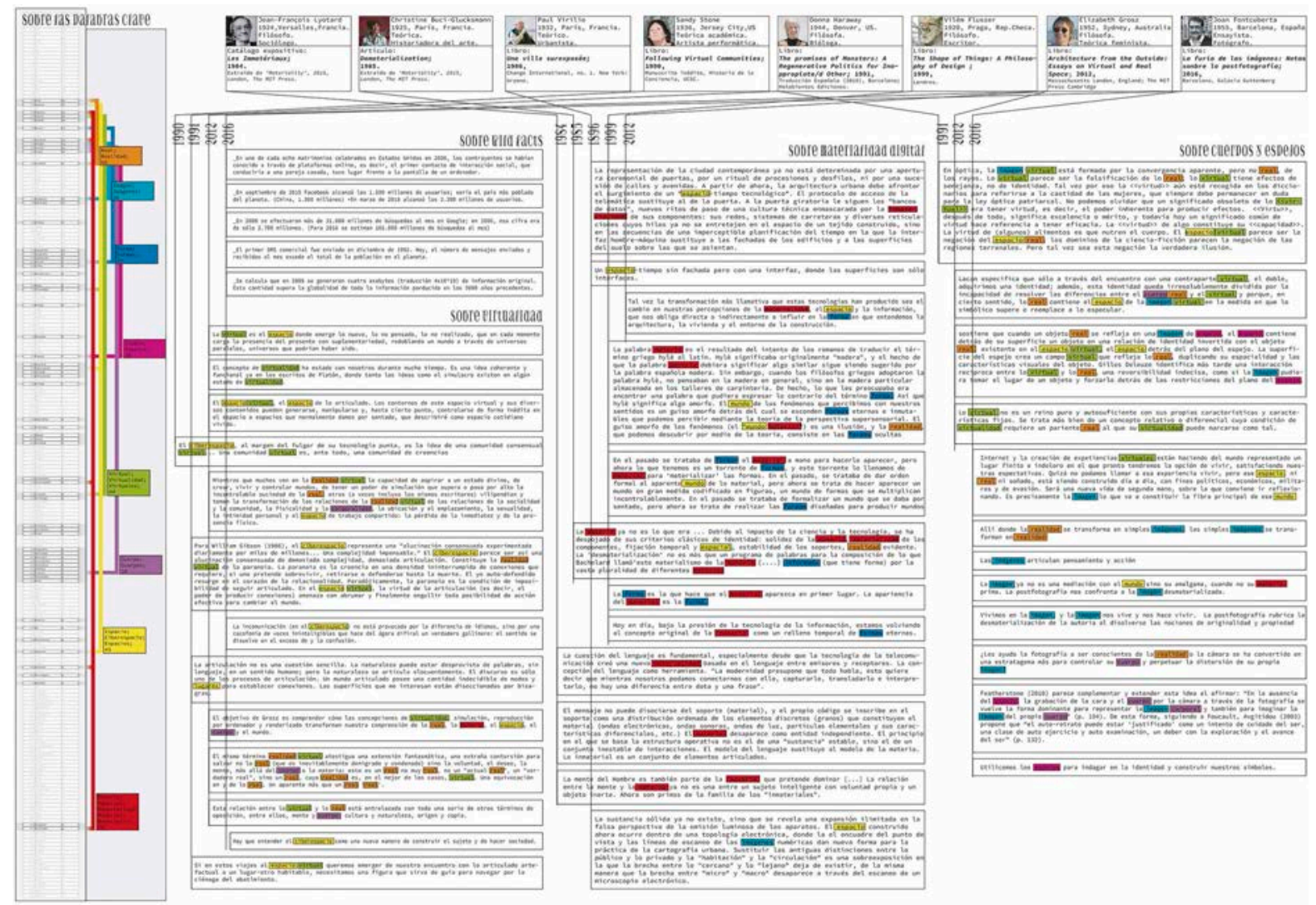

Figure 6. A drawing of the space without the space. Student: Andrea Muniáin Perales. University of Alicante

This way of working, as we see (to finish) in Figure 6, begins and proposes a series of research paths that, with temporality as the central nucleus, allows new perspectives on the analysis and drawing of the city. Is there any way of represent the city without the material space that seems to characterize it permanently? Only with discursive threads of text (which we could understand as pure narration or time without space), the student has created another representation of the space that gives us information about the city that, being traditional and adhering to the laws of geometric representation, we would not be able to get. It is evidenced as another type of diagram since, according to the definition that Sam Jacoby makes of them, "they simultaneously mediate between conceptual thinking and final form" (Jacoby 2016, 12) [10]

\subsection{Final discussion}

Starting from the problematic (impossible to solve) of the representation of temporality in the drawing of the city, and analysing the disconnections and the characteristics of a conscious drawing of its limitations, we have proposed a new methodology. This methodology, based on direct experience and, above all, in the critical position of the student with respect to time, it allows us to obtain some drawings of the city that, understood in temporal terms, represent a finding in the approach path that any architecture student makes with respect to the city. There is no a definitive way of drawing but, at least, we have helped the students to find their own way of explaining the city: this whole of things, relations and people that exceed the material space of traditional drawings.

"Leaving the classroom and entering the city" has work as an emblem: like a vector indicating the direction. Using the databases available online, but being aware that they were uncoordinated with the reality that we intended to draw, we have proposed three lines of research with a common denominator: the direct experience, a critical reflection about time and a conscious synchronization (and, therefore, a controlled disconnection).

The city, that kind of animal to hunt, is as far from our reach as ever but at least, we are able to decide the layers of data with which we want to synchronize our drawings. This way, rethinking the intentions of our teaching exercises, we will be able to find fertile approach modes to the exercise of our profession. Using the instants (points of the time), the overlapping (lines) or letting the complexity of 
time flow through the ubiquitous anachronism, we will build a representation that will contain more than the material space with which, traditionally, the city has been identified.

\section{CONCLUSIONS}

We can synthesize the results in the following ideas, just to summarize:

- The inclusion of the temporal parameter helps us to open a fertile research line during the contemporary drawing of the city.

- The instant, the overlapping and the anachronism can be understood as tools of working over time and of simplifying the problem of representing it, in the same way that the points, the lines and the surfaces are codifications for the material space of architecture and the city.

- The active role of architecture students (and their direct experience of the city) added to an awareness about the complexity of temporality in drawing, allows the results to move away from the traditional urban planning drawings in which space, and geometry, prevailed over the rest of the characteristics of life in society.

\section{ACKNOWLEDGEMENTS}

The present work is developed as part of an $\mathrm{R}+\mathrm{D}+\mathrm{I}$ project entitled "The representation of time in graphic expression", with reference Proyecto-emergente-GRE18-10 and financed, in public concurrence, by the Vice-Rectorate for Research and Transfer of Knowledge of the University of Alicante, Spain.

\section{REFERENCES}

[1] Gaiani, M., "A counter history of thirty years" in Drawing and Architecture 1986-2016, Thirty Years of Research. Chías, P., Cardone, V. (Dirs.), pp.144-155, Universidad de Alcalá, Madrid, España Università degli Studi di Salerno, Italia1 v. (420 pp.) ISBN: 978-84-16599-77-6. Year of publication 2016

[2] Carazo, E., "The role of the drawing in the research and interpretation of urban form" in Drawing and Architecture 1986-2016, Thirty Years of Research. Chías, P., Cardone, V. (Dirs.), pp.32-45, Universidad de Alcalá, Madrid, España - Università degli Studi di Salerno, Italia1 v. (420 pp.) ISBN: 978-84-16599-77-6. Year of publication 2016

[3] Klee, P., Teoría del arte moderno. Ediciones Caldén. Argentina. Year of publication 1976

[4] Weiwei, A. Ai Weiwei speaks with Hans Ulrich Obrist. Penguin books. London. Year of publication 2011

[5] Maynard, P. Drawing distinctions: the varieties of graphic expression. Cornell University Press. UUEE. Year of publication 2005

[6] Didi-Huberman, G. Before Time. Adriana Hidalgo Editores, Buenos Aires 2008. Year of publication 2000

[7] Bachelard, G. La intuición del instante. Fondo de cultura económica. México. 1987. Year of publication 1932

[8] Bergson, H. Obras escogidas. Aguilar S.A., México. Year of publication 1886

[9] Juan Gutiérrez, P.J. "El anacronismo en los conjuntos históricos". En: Actas del II Congreso Internacional sobre Permanencia y Transformación en Conjuntos Históricos: Valencia, 13, 14, 15 y 16 de febrero de 2012. València : Editorial Universitat Politécnica de València, 2012. ISBN 97884-8363-809-5, pp. 8-19. Year of publication 2012

[10] Jacoby, S. Drawing architecture and the urban. John Wiley \& sons. Chichester, West Sussex. Year of publication 2016 